\title{
Project Complexity Influence on Project management performance - The Malaysian perspective
}

\author{
Abdou Saed M ${ }^{1}$, Kuan Yong ${ }^{2}$, Mohammed Othman ${ }^{3, a}$ \\ ${ }^{1}$ Postgraduate student, Faculty of Built Environment, University of Malaya, Kuala Lumpur, Malaysia \\ ${ }^{2}$ Senior lecturer, Department of Architecture, University of Malaya, Kuala Lumpur, Malaysia \\ ${ }^{3}$ Senior lecturer, Department of Quantity Survey, University of Malaya, Kuala Lumpur, Malaysia
}

\begin{abstract}
The project complexity has a negative influence upon project management process particularly on the project performance. The lack of consensus on project complexity is a crucial problem as project complexity is closely correlated with the project management process as well as the project management performance.

Therefore, the understanding of project complexity is of significant importance to address the problem of project management performance. Our extensive literature review enlightened the lack of consensus on project complexity till date and provided a broader view and critical analysis of its underlying concepts. The intention of this paper is to examine the project complexity factors on the project management performance in Malaysia and to provide a review of project complexity and to stimulate debate on this controversial topic. The data was analyzed for a total of 101 respondents involved in this study. Theresults indicated that there is a lack of complexity during understanding and managing project performance. It is concluded that the concept of project complexity is warrents further consideration.
\end{abstract}

Key words: Project Management; Project Complexity; Project performance; Uncertainty

\section{Introduction}

Complexity is considered an essential factor in the field of project management. Nonetheless, the characteristics and nature of project complexity is a controversial debate. While several factors are considered as drivers of project complexity, the studies investigating those are scarce. On one hand, the term "Complexity" is not clearly defined in the literature, instead authors have suggested to pay more attention towards defining and managing the complex projects. On the other hand, it is considered that the project performance is closely related to project complexity. Thus, the project complexity with a firm definition should be precisely measured in order to achieve effective management of projects. However, it is worth mentioning that the complexity can also negatively influence a project performance as well as project outcomes asthe properties emerging from complexity can create certain new prospects. Therefore, it is better to sustain and understand complexity in the project context during project management rather than reducing or avoiding it altogether. it. The purpose of this paper, therefore, is to define project complexity and provide an overview of the existing models and measurement of projects. The systematic defining of those objects, their attributes and their interrelations will enable the readers to define project complexity measure and link it more efficiently with the project performance, subsequently reducing the number and effect of negative outcomes arising from this complexity

\section{Literature Review}

While, construction projects are becoming bigger and more complex, it is important to understand theconcept and management of project complexity. The construction industry has confronted great difficulty in coping with the increasing complexity of major construction projects as well as project management performance $[1,2]$. In spite of extensive research on the concept of complexity, there is no consensus on project complexity. [3] stated that, in fact, the entire intuitive notion of complexity can not be adequately captured by one single concept or definition.

${ }^{a}$ Corresponding author: othman.mohamed@um.edu.my 
The term "complexity" can therefore be perceived through various connotations not only in different fields but alsowithin the same field. In order to assist better modern project management, project complexity needs to be understood and measured efficiently $[4,5]$. Construction projects, particularly mega projects, involve a variety of interconnected factors.. which generate complexity with defined characteristics $[6,7]$. In fact, it is generally agreed that because of the difficulties associated with decisionmaking and goal attainment which appear to stem from complexity, the understanding of complexity is vital for project management [8]. The success of a project therefore ultimately depends upon project performance and its related project complexity [9]. Although the importance of project complexity in project management has been widely acknowledged [4, 10], insufficient objective measures exist for the assessment of project complexity, mainly because the complexity is principally related to the subjectivity of the observer $[11,12]$.

\section{What Is Project Complexity?}

As the sources of complexity are pronounced to be various, dynamic, and uncertain, there is no consensus on complexity [13-15]. The difficulty in defining complexity can be minimised through the identification of its key drivers, although, defining those key drivers is not easier, either in the field of project management or in other domains. [16, 17] reported a lack of agreement on project complexity drivers and little understanding exists about the inter-relations between those drivers. The drivers of complexity depend upon the environment and the context of the project. [16] emphasized on determining the 'context' to be a prerequisite for modelling complexity, which includes time context, work context, motivational context and social context. Considering the project complexity to be composed of different kinds of complexities, such a distinction can lead to efficient project management.[1, 18] for instance, enlisted project complexity through the concepts of differentiation and interdependency of project organization. He determined two types of complexities; organizational complexity i.e. the number of hierarchical levels, the degree of interaction between the project organizational elementsetc and technological complexity i.e. the number of the inputs and outputs, interdependencies between tasks, etc. Moreover, [19] defined complexity incorporating the different aspects as "the property of a model which makes it difficult to formulate its overall behavior in a given language, even when given reasonably complete information about its atomic components and their inter-relations". This definition prominently emphasizes that complexity is relative to the project modeling system. While measuring project complexity, one should be able to define a general measure of this feature independent of the project model, the project complexity measure, otherwise would be a project model complexity measure.

\section{$4 \quad$ Types of Complexity}

\subsection{Organizational complexity}

Organizational complexity, the main type of complexity, includes: allocation of tasks, distribution of the responsibility and authority for decision making and designation of the relationships in terms of reporting and communication [20]. The construction projects are classically characterized by the involvement of numerous distinct and diverse organizations, such as contractors and consultants, for a definite time span. This points to the creation of a multi-organizational structure for the management of construction project temporarily. [19]

\subsection{Technological complexity}

Many authors such as [4] highlighted the absence of unanimity on the technology conceptual definition has frequently been highlighted in the literature. The terminologies of 'technology' and 'task' are interchangeably used quiet frequently i because technology is generally denoted in terms of task performance. Generally, it is justifiable to define technology as a transformation process involving conversion of inputs in outputs [18]. There is employment of knowledge, skills, techniques as well as material means during this transformation process. Technology, therefore, can be classified into three facets: characteristics of knowledge, characteristics of materials and the equipment and sequencing of activities i.e. operations $[1,18]$. Moreover, the technology concept can be applied to any level of the project organization, e.g. the whole organization or a single groupor individual i.e. the entire project production system or the tasks performed by one individual.Technology being multi-dimensional can be classified into two types: complexity and uncertainty [4]. Technological complexity can be operationalized in terms of the difficulties of task performance which would then translate into a diverse interpretation of this technological complexity. This includes wide-ranging attributes of building type, difficulty of location, overlap of construction and design, and interdependence of operations. Furthermore, it has been reported that the concept of uncertainty is inappropriately associated with the difficulties of task performance. Therefore, it seems logical that the technological complexity when defined in terms of differentiation and interdependencies could be more appropriate and practical, [11].

\section{Indicators \& Characteristics of Project Complexity}

Our review of the literature suggested that the factors required for project complexity can be classified into four categories (Figure 1). All of these are indispensable but insufficient for the detrrmination of project complexity. The first family comprises of project size factors, the second contains factors of project variety, the third family addresses factors are related to the project system interdependencies and interrelations. While, the fourth 
deals with context-dependent of the project complexity. The following is a brief explanation of these factors [19].

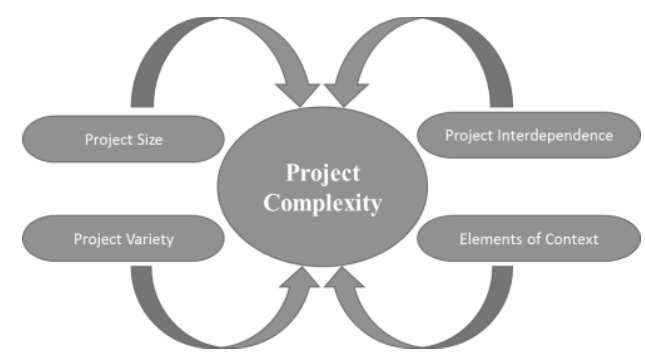

Figure 1. Project Complexity Indicators [19]

\subsection{Size of project}

One of the necessary conditions for project complexity is the size of the project. $[21,22]$ stated that the organizational system should atleast be over a minimum critical size to be labelled as a complex system. The size of the project system, which also defines the parameters and characteristics of complexity, is a one of the main indicators of project complexity.

\subsection{Variety of project}

The project variety is also a key driver of project complexity. [23] emphasized that the diversity in a project is closely associated with the emergent properties and hence the determination of project complexity.

\subsection{Project System Interdependencies}

Many autors highlighted that, interdependencies are likley to be one of the main contribution on project complexity. [24] reported that the interrelationship between various projectcomponents is more intricate than recommended by the usal work breakdown structure of project network. Moreover, the project management traditional tools are likely to be insufficient to certainty of interdependence to be captured. This might be questionable because each element depends and influences the others because of the complete interdependence amongst different components of complexity $[13,21]$.

\subsection{Context-dependence}

$[14,25]$ highlighted contextually as a vital feature of complexity, and a denominator of the complex system. Also reported by [24] who stated that the context and practices of one project are not directly apllicable to other projects with different influential and cultural configurations. Hence, project complexity can neither be analysed nor managed without considering the consequences of the project context.

\section{Analysis of Key Complexity Models}

In our study, we will analyze six models for complexity and draw inferences from them. These models were chosen based on their relevance to the project management context. Although the approaches used are different between project management and change management, the projects are usually attributed to cause changes in the organizations.

\subsection{Turner \& Cochrane Goals and Methods Matrix}

[26] developed a'Goal and Methods Matrix' to assess the potential of project complexity. The projects were classified according to two considerations first how well the goals are defined and second how well the methodology of accomplishing these goals is well-defined. They categorised projects into four varieties and explained the role of the project manager in each variety. They stated that in the absence of certainity of methods, the vital foundations of project management can not be obtained. This study therefore focuses on the goals and methods amongst all other characteristics of complexity and the influence of each method on achieving the goals.

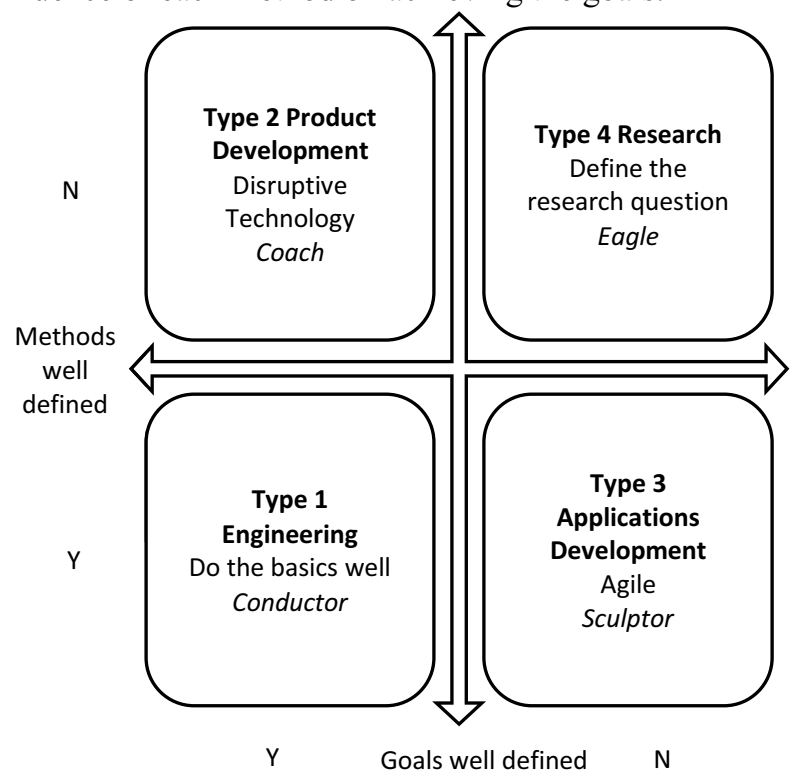

Figure 2. Goals and Methods Matrix [26]

\subsection{Stacey's Agreement \& Certainty Matrix}

The project complexity analyzed by [27] was constructed in two aspects: the level of agreement and the degree of its certainty, Figuer 3. 


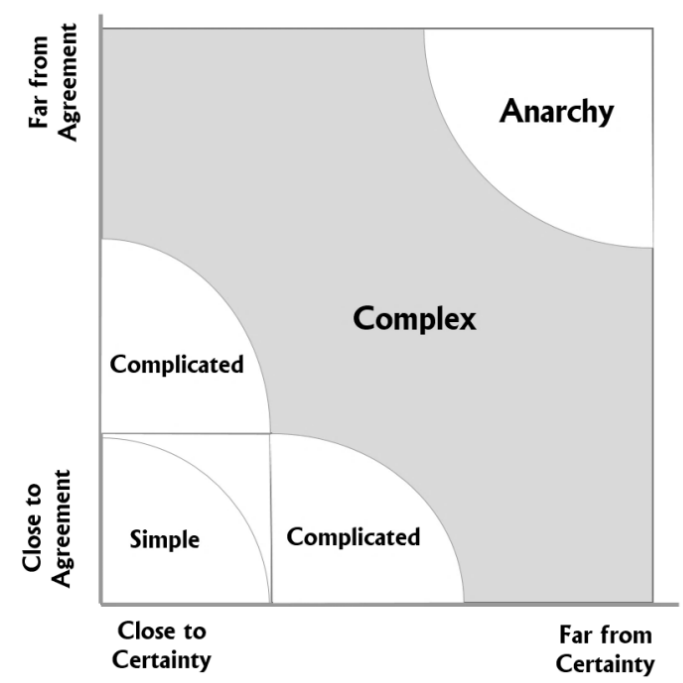

This model aids in the selection of management approaches for a particular subject, which however, is a single part of undertaking a multifaceted project. Stacey's matrix primarily focusses on change, and provides an assistance to handle the projects according to the position in the matrix but it is not extendable for the demonstration of interdependencies.

\subsection{Complexity Model suggested by Terry Williams}

Williams shares the vision of [18] on project complexity and modified it through an additional dimension.

Figure 3. Stacey’s Agreement \& Certainty Matrix [27]

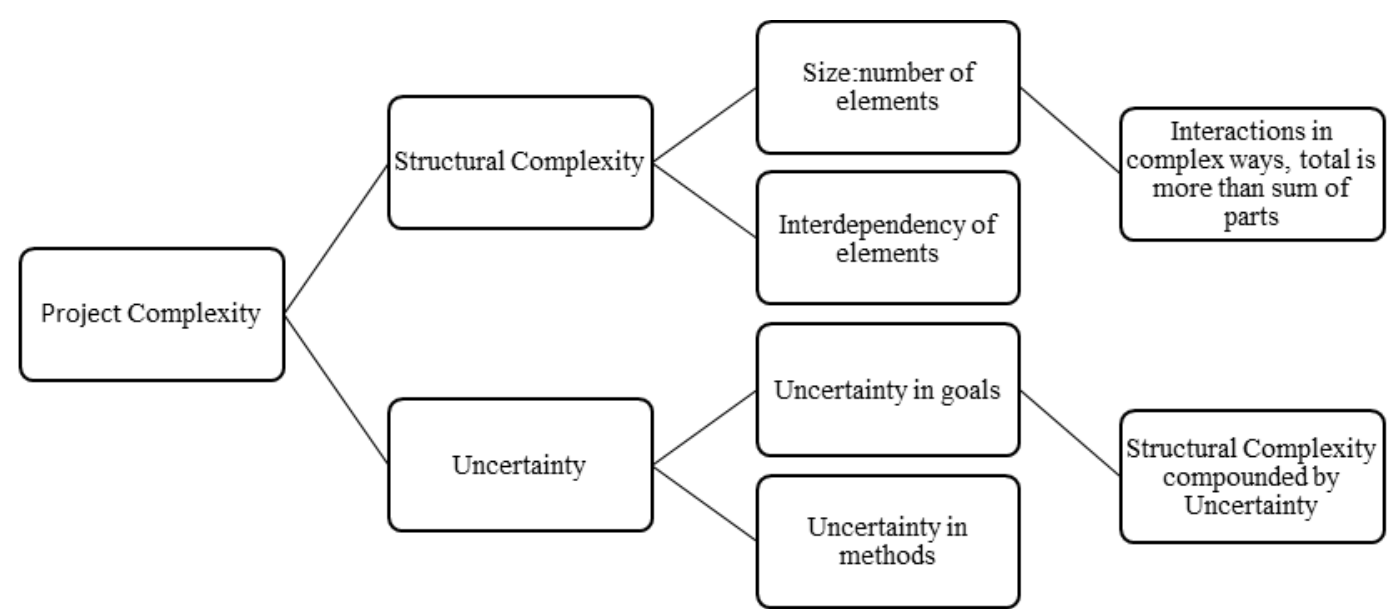

Figure 4. Dimensions of Project Complexity

Another third component which is uncertainty was added to the two existing components of complexity, viz the interdependency as well as the number of elements introduced this was considered as an integral aspect of project complexity because uncertainty augmentsthe complexity of a project [1] Figure 4.

[1] however, suggested that two dimensions in which the total is more than the sum of the parts can sufficiently measure the overall complexity. He pointed out that 'complexity' is steadily increasing in projects and this increase contributes to the failed or unsuccessful projects. The two compounding causative factors are the relationship between project complexity and product complexity and the length of the projects. The new products become structurally more complex with an enhanced degree of inter-element connectivity. Similarly, projects nowadays are more time constrained because of the increasing desire to decrease the market supply time. Figure 4

\subsection{Adam Kahane's approach to complexity}

The [28] approach towards complexity is deeply embedded within the social environment. He distinguishes three types of complexities:

\subsubsection{Dynamic Complexity}

Dynamic complexity denotes that the people involved in the problem perceive things differently thus leading to complicated situations.

\subsubsection{Generative Complexity}

Generative complexity deals with the future, where the future is unaware and uncertain.

\subsubsection{Social Complexity}

It denotes that the people should be elaborated in creating and implementing the solution in order to solve the problems efficiently. However, the individuals involved have dissimilar viewpoints and interests. Thus, the Uprocess was introduced as a methodology by [28] to 
address these challenges.An individual or team has to commence three activities in this U-process methodology:

1. To Sense the existing certainty of the system, which they are part of,

2. To Present and reflect their "inner knowledge" about what is going on and what they have to do, and

3. To realizing, and act swiftly in order to bring forth a new reality.

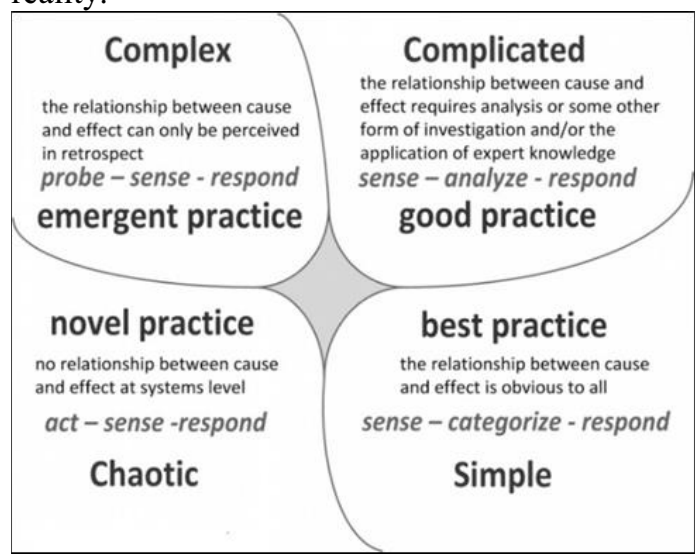

Figure 5. The U Process adapted from [28]

\subsection{Cynefin Decision Making Framework}

[29] constructed another framework that permits the managers to evaluate new things from new perspectives, integrate complex ideas, and targets the real complications entitled as the Cynefin framework. This framework categories the decision into situations according to the root and influence. The next figure shows the characteristics of each context and the ways to tackle them.

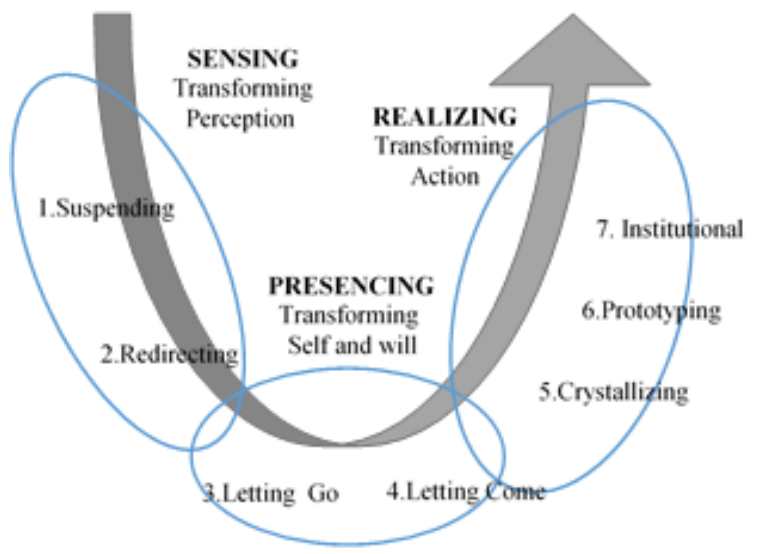

Figure 6. Decisions in Multiple Contexts [29]

This type of complexity creats from a high level of uncertainty of future limitations that may destabilize the project process is termed ad temporal complexity. For
The precise answers can be determined because of the clearer cause and effect relationships seen in the simple and non-complicated domain. On the contrary, people will be required to make a decision based on the imperfect data, with absence of an obvious cause and effect relationship observed in the complex and chaotic domains. Snowden and Boone have identified the complex system by its performance and not its characteristics of each domain within the framework. The typical examples are the unpredictable nature of complex systems along with the cause and effect relationship. Hence, it is descriptive rather than prescriptive in nature.

\subsection{Remington \& Pollack Model}

[30], provided a decent start to categorize complex projects. They highlighted that a profound difference between various types of complexity would assist to select the appropriate tool to manage the project. They suggested four types of project complexity: structural, technical, directional and temporal.

\subsubsection{Structural complexity}

Structural complication creates from a huge scale projects which is divided into minor tasks and single contracts. The engineering, construction and IT projects are more expected to have this type of complexity. This complexity truncates from the difficulty in managing and holding track of an enormous numeral of interrelated events and tasks [30].

\subsubsection{Technical complexity}

Technical complexity is create in projects that have "unknown" and "untried" technical aspects [30]. It is created due to the uncertainty of the outcome. The industrial project and $\mathrm{R} \& \mathrm{D}$ projects encounterthis type of complexity.

\subsubsection{Directional complexity}

Directional complexity can be observed in projects with a high level of change, for example, it might be evident that something must be done to resolve the issue, but that 'something' appears to be uncertain [30].

\subsubsection{Temporal complexity}

example, unexpected legislative changes orrapid changes in technology which make the project more complex. 


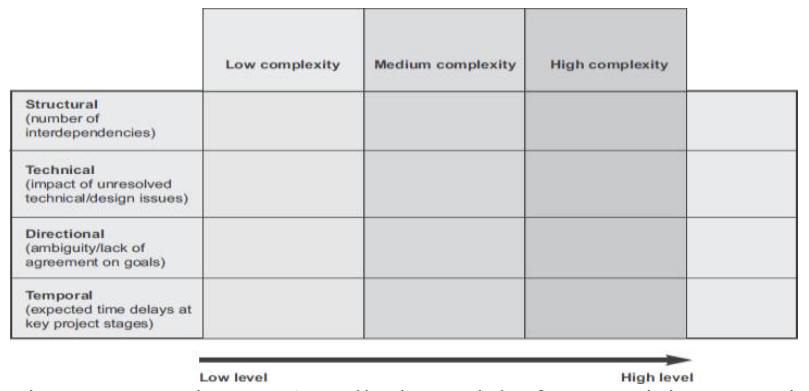

Figure 7. Remington \& Pollack Model of categorizing complex projects

\section{Evaluating Project Complexity}

After reviewing the project complexity models, a total of 33 factors were selected and categorized under project complexity for evaluation. A questionnaire survey was used to determine the factors which extensively contribute to the project complexity and hence the project management performance according to Malaysian project management. The questions were set for the project complexity factors based on our literature review and were distributed randomly amongst the project managers, project management lecturers and project management professionals in Malaysia. Also to ensure that the respondents have appropriate experience they should have been elaborate in complex projects and will be able to provide a effective contribution to the research topic. The response from the project managers was positive, 124 questionnaire responses were received. Nevertheless, a number were inadequate and subsequent data validation the final sample size is 101 it would be $81.5 \%$ of the respondents a total of 101 respondents were recruited from the sample. The level of familiarity of the respondents was evaluated using 5-point Likert scale measurement. Table 1 (Refer to Appendix A for complete Questionnaire)

Table 1. Project Complexity Factors

\begin{tabular}{|l|l}
\hline No. & Project Complexity Factors \\
\hline \multicolumn{2}{|c}{ 1.Technical Category: } \\
\hline $\mathbf{1}$ & Number of project goals \\
\hline $\mathbf{2}$ & Clarity of project goals \\
\hline $\mathbf{3}$ & Uncertainties in scope \\
\hline $\mathbf{4}$ & Strict quality requirements \\
\hline $\mathbf{5}$ & Project duration \\
\hline $\mathbf{6}$ & Number of locations \\
\hline $\mathbf{7}$ & Advanced Technology \\
\hline $\mathbf{8}$ & Number of tasks \\
\hline $\mathbf{9}$ & Variety of tasks \\
\hline $\mathbf{1 0}$ & Uncertainty in methods \\
\hline $\mathbf{1 1}$ & Technical risks \\
\hline
\end{tabular}

\subsection{Respondents profile}

The respondents were segmented into three groups; the first group included the project engineers involved with the project process or planning and supervision process (71\%). The second group included the project management professionals with 10 or more years of experience $(18 \%)$, while the third group included the project management lectures teaching project management at the Malaysian Universities (11\%). Years of experience, size of the project and level of complexity of the projects were the main factors to differentiate amongst the 3 respondent groups (figure 8).

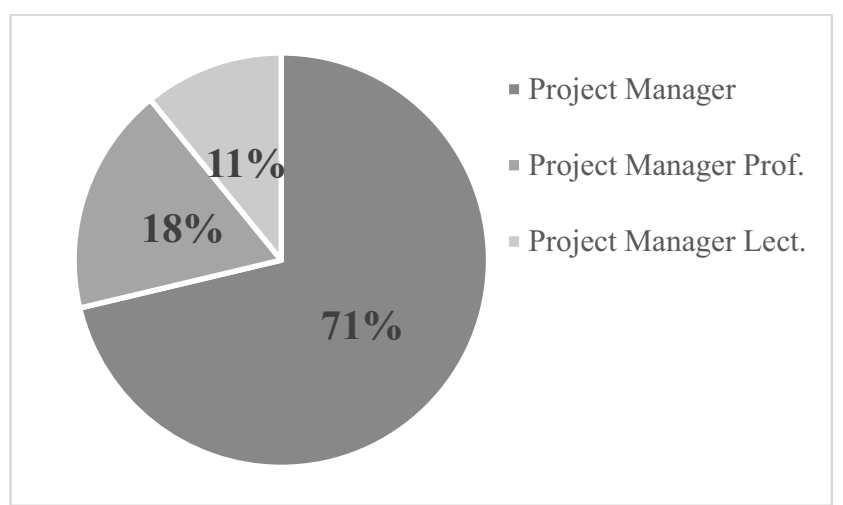

Figure 8. Respondents profile

\subsection{Data Analysis}

The data was analysed by SPSS version 20.0 using exploratory factor analysis (EFA), the approach employed for the analysis was sequential and linear, involving multiple options. Therefore, the following steps for exploratory factor analysis provide areference point to develop clear decision pathways.

\subsection{Sample Size}

There are different opinions and guiding rules for calcultaion of sample size. General guidelines include, the sample size of 100 or above or 300 or more for factor analysis. [31] suggested that solutions with correlation coefficients of $>0.80$ require smaller sample sizes, while others [32] mentioned that inclusion of 50 cases might be adequate for factor analysis.

\subsection{Kaiser-Meyer-Olkin (KMO) \& Bartlett's Test of Sphericity}

The KMO index of 0.50 is considered suitable for factor analysis (range, 0 to 1 ) .. A positive factor analysis means a significant $(\mathrm{p}<.05)$ Bartlett's test of sphericity, Table2 [33]

Table 2. The KMO and Bartlett's Test

\begin{tabular}{|l|l|l|}
\hline \multirow{3}{*}{ Kaiser-Meyer-Olkin Measure of Sampling Adequacy } & 0.808 \\
\hline \multirow{3}{*}{ Bartlett's Test of Sphericity } & Approx. Chi-Square & 1337.140 \\
\cline { 2 - 3 } & df & 528 \\
\cline { 2 - 3 } & Sig. & 0.000 \\
\hline
\end{tabular}




\subsection{Extraction Method}

[34] noted that Principal Component Analysis (PCA) being the default method in many statistical programs, is commonly used in Exploratory Factor Analysis (EFA). However, where no priori theory or model exists, PCA is recommended to establish the preliminary solutions in EFA.

\subsubsection{Cumulative Percentage of Variance}

The table below demonstrates a cumulative percentage of $53.2 \%$ variance and 6 components (factors) having an eigenvalue $>1$. These results are adequate, as the explained variance is commonly as low as 50-60\%. [35] as shown in Table 3. (Refer to Appendix B for the complete table)

Table 3. Total Variance Explained

\begin{tabular}{|c|c|c|c|c|c|c|c|}
\hline \multirow[b]{2}{*}{ Component } & \multicolumn{3}{|c|}{ Initial Eigenvalues } & \multicolumn{3}{|c|}{ Extraction Sums of Squared Loadings } & \multirow{2}{*}{$\begin{array}{l}\text { Rotation } \\
\text { Sums of } \\
\text { Squared } \\
\text { Loadings }\end{array}$} \\
\hline & Total & $\%$ of Variance & Cumulative $\%$ & Total & $\%$ of Variance & Cumulative $\%$ & \\
\hline 1 & 9.316 & 28.232 & 28.232 & 9.316 & 28.232 & 28.232 & 5.828 \\
\hline 2 & 2.181 & 6.610 & 34.842 & 2.181 & 6.610 & 34.842 & 5.149 \\
\hline 3 & 1.799 & 5.452 & 40.294 & 1.799 & 5.452 & 40.294 & 5.122 \\
\hline 4 & 1.514 & 4.589 & 44.883 & 1.514 & 4.589 & 44.883 & 4.830 \\
\hline 5 & 1.397 & 4.234 & 49.117 & 1.397 & 4.234 & 49.117 & 3.930 \\
\hline
\end{tabular}

\subsubsection{Scree Test}

The Scree plot and eigenvalues produced a departure from linearity coinciding with a 5 -factor result. Hence, this Scree Test indicateed that the data should be analysed for 5 factors among the total 33 factors included initially.

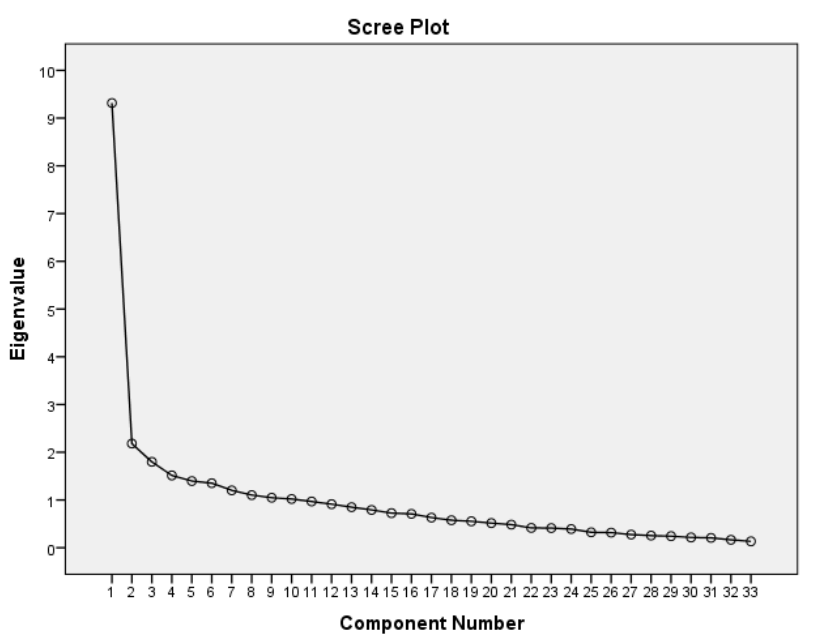

Figure 9. The Scree Plot shows 6 factors $>1.0$

\subsubsection{Selection of Rotational Method}

Rotation Method: Promax with Kaiser Normalization, rotation was converged in 10 iterations as shown in the component matrix. (Refer to Appendix B)

\subsubsection{Interpretation}

Interpretation involves examining the variables attributed to a factor, and giving that factor a name or theme. To indicate those factors combined together, to explain the majority of the responses the Pattern Matrix, was examined five factors were produced (Table 4).

Table 4. The Pattern Matrix

\begin{tabular}{|l|c|c|c|c|c|}
\hline \multirow{2}{*}{} & \multicolumn{5}{|c|}{ Component } \\
\cline { 2 - 6 } & \multicolumn{1}{|c|}{1} & 2 & 3 & 4 & 5 \\
\hline Weather conditions & .824 & & & & \\
Number of locations & .731 & & & & \\
Interference between & .609 & & & & \\
existing sites & .563 & & & & \\
Number of different & & & & & \\
languages & .560 & & & & \\
Clarity of project goals & & & & &
\end{tabular}

\section{Results and Findings}

Initially, the factorability of the correlation between 33 items was examined using several well-recognized criteria for the factorability assessment. Firstly, it was observed that many items correlated at least 0.3 with one other item, suggesting a reasonable factorability (see Appendix B). Secondly, the Kaiser-Meyer-Olkin measure of sampling adequacy was 0.81 , which is above the recommended value of 0.6 , and Bartlett's test of sphericity was also significant $(\chi 2(528)=1337.14, p<.05)$. Finally, the communalities were all above 0.3 (see Appendix B), further confirming that each item shared some common variance with the other items. Given these overall indicators, factor analysis was deemed suitable with all the 33 items.

Principal Components Analysis (PCA) was employed to identify and figure intricate scores for the factors addressing project complexity. Total variance explained by using Promax with Kaiser normalization rotations of the factor-loading matrix was $53.2 \%$ according to the initial eigenvalues. Fourteen items were eliminated because they did not contribute to a simple factor structure and failed to meet the minimum criteria of primary factor loading of 
$\geq 0.5$, and no cross-loading of $\geq 0.4$ as shown in Table 4 (Refer to Appendix B for the complete table).

\section{Discussion}

The data were subjected to factor analysis using principal components extraction method and rotation method Promax with Kaiser Normalization. All KMO values for the individual item $(>0.90)$ were over 0.5 and the KaiserMeyer-Olkin Measure (KMO) was 0.81, indicating that the data was sufficient for Exploratory Factor Analysis (EFA). Using an eigenvalue cut-off of 1.0, five factors explained an increasing variance of $53.2 \%$. And scree plot confirmed the results of those five factors. The below table displays the factor loading after rotation using a significant factor measure of 0.50 (Table 5).

Table 5. Mapping the results

\begin{tabular}{|c|c|c|c|c|c|c|}
\hline & Factors & Environmental & Operational & Organizational & Technical & Team \\
\hline 1 & Weather conditions & .824 & & & & \\
\hline 2 & Number of locations & .731 & & & & \\
\hline 3 & $\begin{array}{l}\text { Interference between } \\
\text { existing sites }\end{array}$ & .609 & & & & \\
\hline 4 & $\begin{array}{l}\text { Number of different } \\
\text { languages }\end{array}$ & .563 & & & & \\
\hline 5 & $\begin{array}{l}\text { Clarity of project } \\
\text { goals }\end{array}$ & .560 & & & & \\
\hline 6 & Project duration & & .697 & & & \\
\hline 7 & $\begin{array}{ll}\text { Availability } & \text { of } \\
\text { financial sources } & \\
\end{array}$ & & .692 & & & \\
\hline 8 & $\begin{array}{ll}\text { Strict } & \text { quality } \\
\text { requirements }\end{array}$ & & .665 & & & \\
\hline 9 & Variety of tasks & & .567 & & & \\
\hline 10 & $\begin{array}{l}\text { Uncertainty in } \\
\text { methods }\end{array}$ & & & .722 & & \\
\hline 11 & Size of project team & & & .638 & & \\
\hline 12 & $\begin{array}{l}\text { Involvement of } \\
\text { different time-zones }\end{array}$ & & & .564 & & \\
\hline 13 & Political influence & & & .543 & & \\
\hline 14 & $\begin{array}{l}\text { Lack of experience in } \\
\text { the country }\end{array}$ & & & & .720 & \\
\hline 15 & Level of competition & & & & .699 & \\
\hline 16 & Technical risks & & & & .670 & \\
\hline 17 & $\begin{array}{l}\text { Lack of experience } \\
\text { with partners }\end{array}$ & & & & & .777 \\
\hline 18 & $\begin{array}{l}\text { Lack of resources \& } \\
\text { skills }\end{array}$ & & & & & .694 \\
\hline \multirow[t]{2}{*}{19} & $\begin{array}{l}\text { Number of project } \\
\text { goals }\end{array}$ & & & & & .552 \\
\hline & Eigenvalues & 9.3 & 2.2 & 1.8 & 1.5 & 1.4 \\
\hline & $\%$ of Variance & $28.2 \%$ & $6.6 \%$ & $5.5 \%$ & $4.6 \%$ & $4.2 \%$ \\
\hline
\end{tabular}

The new 5 factors explained in the above table showed that: (i) Weather conditions, number of locations, interference between existing sites, number of different languages and clarity of project goals were the complex variables under "Environmental Complexity Factor". (ii) Project duration, availability of financial sources, strict quality requirements and variety of tasks were the complex variables under "Operational Complexity factor". (iii) Uncertainty in methods, size of the project team, involvement of different time-zones and political influence were the complex variables under “Organizational Complexity factor".(iv)Lack of experience in the country, level of competition and Ttechnical risks were the complex variables under
“Organizational Complexity factor”. (v) Finaly, lack of experience with partners, lack of resources \& skills and number of project goals were the complex variables under Team Complexity factor.

\section{Conclusion}

From the previous literature on project complexity factors within the Malaysian project management, the following highlights should be taken into consideration. The deficiency of project complexity framework due to lack of knowledge about their effect on the project process and hence project outcomes. Efficient complexity measures should be elaborated and clearly 
explained at the local level whichmay lead to a better vision of project complexity influence on project outcomes and consequenlty the better project performance in Malaysia. The successful management of projects depends on the appropriate actions taken according to certain critical characteristics of the projects. The authors propose that the project complexity should be understood in terms of interdependencies and diversity. The consequence to project complexity is integration by direction, control and communication. The concept of project complexity, therefore deserves further consideration and extensive research in future. The purpose of the paper was to provide a review of project complexity and to stimulate a conclusion in this lagging subject. As projects have turn out to be increasingly complex there will be a growing concern about the concept of project complexity and its influence on the project management process. The complexity has to be managed effectively in order to achieve greater levels of project performance. However, managing complexity does not mean avoiding or reducing it entirely, a good project manager should be able to manage complexity every time by maintaing the upper and lower levels of project complexity. For the project managers to reach this complexity level, efficient complexity models and measures need to be elaborated and implicated. Moreover, by clearing the concept at the local level and giving a better vision of the propagation of change by navigating through the model at local level, the project complexity influence on project evolution could be understood for a better project performance in Malaysia. One should be able to achieve the objectives proficiently to assess the impact of change or any decision and simulate different scenarios of evolution.

\section{References}

1. Williams, T., Modelling complex projects. 2002.

2. Bosch-Rekveldt, M., Managing project complexity. Delft Centre for Project Management, the Netherlands., 2011. ISBN 978-94-91005-00-8.

3. Sinha, S., B. Kumar, and A. Thomson, Measuring project complexity: a project manager's tool. Architectural Engineering and Design Management, 2006. 2(3): p. 187-202.

4. Vidal, L.-A. and F. Marle, Understanding project complexity: implications on project management. Kybernetes, 2008. 37(8): p. 1094-1110.

5. Bryde, D., Perceptions of the impact of project sponsorship practices on project success. International Journal of Project Management, 2008. 26(8): p. 800-809.

6. Lucas, C., The philosophy of complexity. On-line at www. calresco. org, retrieved August, 2005. 8: p. 2011.

7. Chan, A.P., D. Scott, and A.P. Chan, Factors affecting the success of a construction project. Journal of construction engineering and management, 2004.

8. Remington, K., R. Zolin, and R. Turner. A model of project complexity: distinguishing dimensions of complexity from severity. in Proceedings of the 9th International Research Network of Project Management Conference. 2009. IRNOP.

9. Chan, A.P., D. Scott, and A.P. Chan, Factors affecting the success of a construction project. Journal of construction engineering and management, 2004. 130(1): p. 153-155.

10. Parsons-Hann, H.a.L., K. , Measuring requirement complexity to increase the probability of project success. Proceedings of ICEIS 2005, Miami, Florida, USA, 2005. pp. 434-8.

11. Corning, P.A., Complexity is just a word! Technological Forecasting and Social Change, 1998. 59(2): p. 197-200.

12. Pich, M.T., Loch, C.H. and de Meyer, A., On uncertainty, ambiguity, and complexity in project management. Management Science, 2002. Vol. 48 No. 8(pp. 1008-23).

13. Calinescu, A., et al., Applying and assessing two methods for measuring complexity in manufacturing. Journal of the Operational Research Society, 1998: p. 723-733.

14. Chu, D., R. Strand, and R. Fjelland, Theories of complexity. Complexity, 2003. 8(3): p. 19-30.

15. Jaafari, A., Project management in the age of complexity and change. Project Management Journal, 2003. Vol. 34 No. 4: p. pp. 47-57.

16. Sinha, S., B. Kumar, and A. Thomson, Complexity measurement of a project activity. International Journal of Industrial and Systems Engineering, 2011. 8(4): p. 432-448.

17. Koivu, T., Nummelin, J., Tukiainen, S., Tainio, R. and Atkin, B. , Institutional complexity affecting the outcomes of global projects. VTT Working Papers 14, VTT, Espoo, 2004.

18. Baccarini, D., The concept of project complexitya review. International Journal of Project Management, 1996. 14(4): p. 201-204.

19. Edmonds, B., Syntactic measures of complexity. 1999, University of Manchester.

20. Laurikkala, H., Puustiner, E., Pajarre, E. and Tanskanen, K., Reducing complexity of modelling in large delivery projects. Proceedings of the International Conference on Engineering Design, ICED'01, Glasgow, 2001. Vol. 1, Professional Engineering Publishing, Bury St Edmunds, pp. 165-72.

21. Corbett, L., J. Brockelsby, and C. Campbell-Hunt, Tackling industrial complexity. Tackling Industrial Complexity, 2002: p. 83-96.

22. Cicmil, S. and D. Marshall, Insights into collaboration at the project level: complexity, social interaction and procurement mechanisms. Building Research \& Information, 2005. 33(6): p. 523-535.

23. Jones, B.S. and P. Anderson, Diversity as a determinant of system complexity. Complexity in Design and Engineering, 2005.

24. Koivu, T., et al., Institutional complexity affecting the outcomes of global projects. 2004. 
25. Genelot, D., Manager dans la complexité: réflexions à l'usage des dirigeants. 2001: INSEP éditions.

26. Turner, J.R. and R.A. Cochrane, Goals-andmethods matrix: coping with projects with ill defined goals and/or methods of achieving them. International Journal of Project Management, 1993. 11(2): p. 93-102.

27. Stacey, R.D., Complexity and creativity in organizations. 1996: Berrett-Koehler Publishers.

28. Kahane, A., Solving tough problems: An open way of talking, listening, and creating new realities. 2004: Berrett-Koehler Publishers.

29. Snowden, D.J. and M.E. Boone, A leader's framework for decision making. harvard business review, 2007. 85(11): p. 68.

30. Remington, K. and J. Pollack, Tools for complex projects. 2007: Gower Publishing, Ltd.

31. Guadagnoli E, V.W., Relation of sample size to the stability of component patterns. Psychological Bulletin, 1988. 103(2):265-75.

32. Sapnas KG, Z.R., Minimizing sample size when using exploratory factor analysis for measurement. Journal of Nursing Measurement, 2002. 10(2):135-53.

33. Tabachnick BG, F.L., Using Multivariate Statistics. Boston: Pearson Education Inc, 2007.

34. B., T., Exploratory and confirmatory factor analysis: understanding concepts and applications. American Psychological Association, 2004.

35. Pett MA, L.N., Sullivan JJ. , Making Sense of Factor Analysis: The use of factor analysis for instrument development in health care research. Sage Publications Inc, 2003. 